\title{
PERSEPSI MASYARAKAT TENTANG MANFAAT BUDAYA DAN KESEHATAN MENGONSUMSI TAMBELO, SIPUT DAN KERANG DI MIMIKA, PAPUA
}

\author{
(Perception on Curtural and Health Benefit of Consuming Typical Molluscas \\ by Mimika's Estuary Community, Papua) \\ Hardinsyah $^{1}$, Agus Sumule ${ }^{2}$, J ohn Letsoin ${ }^{2}$ dan J aan Barausau ${ }^{3}$
}

\begin{abstract}
Some local foods have cultural and health benefits. Mollusca such as tambelo - a mangrove worm, snail and shell (TSS) contain essential amino acids and micronutrients required for optimum health. This study is aimed to analyse the perception of local community at estuary of Mimika on culture and health benefits of consuming the TSS. For this purpose 158 people of the 12 estuary villages, which consist of children (1-11 yrs), teenages (12-19 yrs) and adults ( $>20 \mathrm{yrs}$ ) from both sexes, were selected as subjects. The data collected covers socio-economic of the family, perception of subjects on cultural and health benefits of the TSS, and ways to consume the TSS. The results showed that the TSS has significant intangible benefits for culture and health of Mimika's estuary community. In terms of culture, tambelos (Bactronophorus thoracites and Bankia orcutti) are used as a special entry food for local custome rituals; and both snails (Telecopium telescopiu, Nerita balteata, dan Naqueita capicana) and shells (Geloina cf coaxan dan Geloina, sp) are used as a special main menu for lokal costume rituals. In terms of health, the general health benefits of eating TSS is for strengthening and maintaining optimum stamina. In addition, Geloina, sp (a shell) is used for wound healing; and Bactronophorus thoracites (a tambelo), which is called as "kamoro pil" by Kamoro ethnic, is consumed to have better production of breastmilk, and to have prevention and theurepetic effects of malaria, cough, flu, rheumatic and backache, as well as approdisiac and appetite effects. Tambelo is consumed freshly, while snails and shell are steamed or roasted before they are consumed.
\end{abstract}

Keywords: health benefit, culture benefit, snail and shell, Bactronophorus thoracites

\section{PENDAHULUAN}

\section{Latar Belakang}

Sejak keberadaan manusia di bumi, ekosistem telah mendukung keberlansungan kehidupan manusia (Ends \& Gormukh, 2005). Sebaliknya pemanfaatan berbagai jenis sumberdaya hayati oleh manusia dalam suatu ekosistem berkaitan erat dengan faktor lingkungan fisik, budaya dan sosial ekonomi masyarakat (Mitchell, Setiawan \& Rahmi, 2003). Dalam konteks ini pemahaman akan interaksi manusia dengan lingkungannya menjadi penting untuk memberikan perlindungan dan pemulihan terhadap ekosistem, sebagai salah satu cara menjamin keberlangsungan dan kesejahteraan manusia dalam ekosistem tersebut.

Kabupaten Mimika adalah salah satu kabupaten baru di provinsi Papua. Kabupaten yang ibu kotanya Timika ini, memiliki luas

\footnotetext{
${ }^{1}$ Staf Pengajar Departemen Gizi Masyarakat, Fakultas Ekologi Manusia (FEMA), IPB

${ }^{2}$ Staf Pengajar Fakultas Pertanian (Faperta), Universitas Papua.

${ }^{3}$ Staf Lembaga Bantuan Hukum (LBH), Kabupaten Mimika.
}

wilayah $18209 \mathrm{~km}^{2}$ dan pada tahun 2000 berpenduduk sebanyak 68810 jiwa (http://id. wikipedia.org/ wiki/Kabupaten_Mimika).

Penduduk lokal Kabupaten Mimika terdiri dari dua suku besar, yaitu Suku Amungme yang bermukim di daerah pegunungan dan kelompok Suku Kamoro di dataran rendah dan muara. Kabupaten Mimika memiliki kondisi alam dengan agroekologi yang unik. Di bagian utara adalah pegunungan diselingi jurang-jurang terjal dan memiliki satu di antara dua salju abadi di wilayah ekuator dunia. Sementara dataran rendahnya adalah hutan dan daerah pertanian tradisioanal di sekitar pemukiman penduduk. Di bagian selatan terdapat ekosistem muara yang ditumbuhi hutan sagu dan bakau.

Di daerah muara bagian Selatan Kabupaten Mimika bermukim sekitar 3000 penduduk lokal, yang sebagian besar adalah Suku Kamoro, dan sedikit suku Sempang. Pada umumnya makanan dan kehidupan penduduk lokal di muara Mimika tergantung pada sumberdaya alam yang tersedia di kawasan ini melalui kegiatan meramu, nelayan dan bertani Daerah muara Mimika telah lama menjadi tempat pencarian atau penangkapan ikan, 
kepiting, udang dan aneka moluska bagi konsumsi dan ekonomi masyarakat setempat. Moluska tertentu seperti tambelo, siput dan kerang hidup subur di perairan muara kawasan bakau (Hardinsyah et al., 1998).

Faktor ekonomi menyebabkan hasil perairan dan laut seperti udang, kepiting dan ikan oleh masyarakat setempat lebih baik dijual untuk mendapatkan uang guna dibelanjakan bagi pemenuhan kebutuhan lainnya sedangkan lauk pauk yang dikonsumsi masyarakat setempat pada umumnya biota yang mereka sukai dan kurang bernilai di pasar komersial, seperti berbagai jenis ulat bakau (tambelo), siput dan kerang. Tambelo, siput dan kerang menjadi bagian dari pola konsumsi pangan masyarakat lokal di muara Mimika (Hardinsyah et al., 2006). Bahkan berbagai informasi yang diperoleh dari tokoh masyarakat menunjukkan bahwa tambelo, siput dan kerang tidak hanya sekedar pemenuhan kebutuhan pangan bagi masyarakat lokal, tetapi juga mempunyai peran budaya dan kesehatan. Selama ini belum ada penelitian tentang manfaat budaya dan kesehatan tambelo, siput dan kerang yang dikonsumsi penduduk muara Mimika.

\section{Tujuan}

Tujuan penelitian ini adalah untuk mengetahui persepsi masyarakat tentang manfaat budaya dan kesehatan menggunakan tambelo, siput dan kerang pada masyarakat lokal di muara Selatan Kabupaten Mimika, Papua.

\section{METODE PENELITIAN}

\section{Desain, Tempat dan Waktu Penelitian}

Desain cross sectional study dengan metode survai diterapkan pada penelitian ini. Survai dilakukan kepada anggota keluarga yang meliputi anak, remaja dan dewasa, baik pria maupun wanita di 12 desa di Kawasan Muara di sebelah Selatan Kabupaten Mimika.

Dua belas desa ini dipilih secara sengaja atau purposif, yaitu desa-desa muara yang secara historis dan sebagian saat ini merupakan lokasi pencarian atau penangkapan tambelo, siput dan kerang (TSK) oleh penduduk setempat. Kedua belas desa tersebut adalah Kali Kopi, Pad XI, Pulau Karaka, Omawita dan Fanamo, Otakwa, Paumako, Kaugapu, Tipuka, Aikawapuka, Mioko dan Atuka. Kegiatan pengumpulan data di lapang berlangsung pada Mei tahun 2000.

\section{Prosedur Penarikan Contoh}

Contoh adalah penduduk lokal yang dipilih secara purposif dengan mempertimbangkan anggota keluarga yang ada di rumah dan bersedia diwawancarai saat kunjungan rumah oleh pewawancara. Mempertimbangkan jumlah penduduk yang relatif kecil di suatu desa (200400 jiwa) dan berdasarkan informasi awal dari tokoh masyarakat bahwa penduduk lokal sering mengonsumsi TSS dan tidak bersifat musiman, maka ditetapkan jumlah contoh per desa adalah 30 orang (10 contoh untuk setiap kelompok umur dan 15 contoh untuk setiap jenis kelamin). Contoh distratifikasi menurut umur dan jenis kelamin, yaitu anak umur 2-10 tahun, remaja umur 11-19 tahun dan dewasa umur 20 tahun atau lebih, yang seimbang menurut jenis kelamin (laki-laki dan perempuan).

Tidak diperkenankan menarik contoh lebih dari satu orang pada kelompok umur yang sama dari suatu keluarga. Responden atau pihak yang diwawancarai bagi contoh usia anak-anak adalah ibu dari anak yang menjadi contoh. Jumlah contoh akhir yang mempunyai data yang lengkap untuk diolah adalah 358 contoh dengan rincian 100 orang anak, 129 remaja dan 129 dewasa (Tabel 1 ).

Tabel 1. Sebaran J umlah Contoh menurut KeIompok Umur dan Desa

\begin{tabular}{|l|r|r|r|r|}
\hline \multicolumn{1}{|c|}{ Desa } & Anak & Remaja & Dewasa & Total \\
\hline 1. Kali Kopi & 6 & 12 & 12 & 30 \\
\hline 2. Pad XI & 6 & 12 & 12 & 30 \\
\hline 3. Karaka & 6 & 12 & 12 & 30 \\
\hline 4. Omawita & 4 & 11 & 14 & 29 \\
\hline 5. Fanamo & 10 & 11 & 9 & 30 \\
\hline 6. Otakwa & 10 & 10 & 10 & 30 \\
\hline 7. Tipuka & 11 & 8 & 11 & 30 \\
\hline 8. Kaugapu & 5 & 15 & 10 & 30 \\
\hline 9. Paumako & 12 & 7 & 10 & 29 \\
\hline 10. Aikawapuka & 10 & 10 & 10 & 30 \\
\hline 11. Mioko & 10 & 10 & 10 & 30 \\
\hline 12. Atuka & 10 & 11 & 9 & 30 \\
\hline Total & 100 & 129 & 129 & 358 \\
\hline
\end{tabular}

\section{Pengolahan dan Analisis Data}

Pengumpulan data dilakukan dengan Kelompok Diskusi Terarah (FGD) dengan tokoh masyarakat di setiap desa, dan wawancara lansung kepada subjek atau contoh yang terpilih. Pada FGD dikumpulkan informasi awal tentang jenis-jenis TSK yang biasa dikonsumsi masyarakat dan manfaat TSK bagi masyarakat. Pada kegiatan wawancara kunjungan rumah, 
dikumpulkan informasi meliputi identitas contoh, keadaan sosial ekonomi keluarga contoh, jenis, jenis, frekuensi dan jumlah konsumsi TSK serta hasil perairan lainnya; persepsi responden tentang manfaatnya dalam konteks budaya dan kesehatan, cara mengonsumsi, cara memperoleh dan lokasi pencariannya. Pewawancara berpendidikan sarjana yang telah banyak pengalaman studi lapang di Papua. Manfaat TSK dalam konteks budaya adalah penggunaan jenis-jenis TSK dalam berbagai acara ritual adat oleh masyarakat setempat; dan manfaat TSK dalam konteks kesehatan adalah penggunaan jenis-jenis TSK yang diyakini masyarakat berefek promotif bagi kesehatan atau berefek preventif dan penyembuhan penyakit atau gangguan kesehatan masyarakat.

Enumerator adalah staf muda Faperta UNCEN Monokwari (kini berkembang menjadi UNIPA) dan staf LSM di Mimika minimal berpendidikan sarjana di bidang sosial atau perikanan yang telah berpengalaman mengumpulkan data survai di Papua. Sebelum turun lapang untuk wawancara, enumerator dilatih tentang metode dan kuesioner penelitian ini.

Pengolahan data dilakukan dengan menyalin data dari kuesioner ke lembar pindah (transfer sheet) sesuai buku kode (code book) yang telah dipersiapkan. Hal ini dimaksudkan untuk meminimalkan kesalahan entri data. Kemudian dilakukan entri data oleh para peneliti dan enumerator secara berpasangan dengan maksud meminimalisasi kesalahan. Hasil olah data disajikan dalam bentuk tabel dan grafik. Pemaparan hasil kajian tentang keadaan sosial ekonomi keluarga dan jenis dan jumlah TSK yang dikonsumsi dipublikasi pada artikel terpisah (Hardinsyah et al. 2006).

\section{HASIL DAN PEMBAHASAN}

\section{Manfaat dalam Budaya}

Sebagian besar contoh di hampir semua desa penelitian menyatakan bahwa tambelo, siput, dan kerang (TSK) merupakan bagian yang penting dalam pesta adat atau mempunyai manfaat khusus dalam konteks budaya masyarakat setempat (Gambar 1). Hanya di Desa Kaugapu penduduk tidak banyak lagi yang memanfaatkan TSK dalam acara adat. Salah satu alasannya adalah semakin sulit dan jauh untuk mencari TSK serta mengganggap hal tersebut bukan suatu keharusan.

Salah satu manifestasi pemanfaatan TSK dalam budaya suku Kamoro dan Sempan adalah pesta adat inisiasi memasuki usia remaja.
Ritual adat ini bagi suku Kamoro disebut Karapao, dan bagi suku Sempan ritual adat ini disebut Arapao. Pada prinsipnya tujuan kedua acara adat ini adalah sama, yaitu mengantarkan, memaklumatkan dan mendoakan setiap anak yang memasuki usia remaja agar menjadi generasi muda yang kuat dan sehat, serta matang secara mental. Pada acara adat ini tambelo dijadikan sebagai makanan pembuka (entri) kemudian siput dan kerang sebagai makanan lauk utama. TSK tidak saja disuguhkan atau diberikan kepada orang yang berbahagia atau yang sedang diupacarakan, tetapi juga disuguhkan kepada tamu yang hadir. Tanpa keberadaan sajian kerang, siput, dan tambelo, pesta inisiasi itu tidak akan dilaksanakan. Acara dipimpin oleh tokoh adat yang disaksikan oleh keluarga anak yang diinisiasi serta warga desa yang hadir.

Tidak semua jenis TSK dapat disajikan pada pesta adat. Hanya tambelo, siput dan kerang tertentu yang bermanfaat pada acara budaya ini. Tambelo Bactronophorus thoracites dan Bankia orcutti, siput Telescopium telescopium, Nerita balteata dan Naquueita capulina serta kerang Geloina sp dan Geloina of Coaxan yang digunakan untuk makan upacara adat. Disamping alasan budaya, jenis-jenis TSK ini merupakan TSK yang disukai oleh penduduk lokal di muara Mimika (Hardinsyah et al., 2006).

Seperti halnya moluska dan hewan bentos, tambelo, siput dan kerang mengandung banyak asam-asam amino dan asam-asam lemak esensial; juga mengandung vitamin B6, B12, kolin dan niasin serta mineral kalsium, fosfor, besi, zink, selenium dan magnesium (Insel, Turner \& Ross, 2002). Menurut Gibney et al. (2002), zat-zat gizi tersebut sangat bermanfaat untuk mencegah anemia, optimalisasi peredaran darah, pertumbuhan tulang dan jaringan syaraf serta pembentukan ber- bagai enzim, hormon dan imunitas yang men- jadi modal untuk memiliki tubuh berstamina dan sehat. Jadi dari segi gizi, budaya makan tambelo, siput dan kerang dalam kehidupan dan dalam ritual adat suku Kamoro dan Sempan, seperti inisiasi remaja (Karapao dan Arapao) sangat rasional, bahkan penting untuk hidup lebih berstamina dan sehat.

Manifestasi budaya lainnya yang memiliki implikasi khusus dengan tambelo adalah ritual Kaware dan Ndoko di Mioko. Ritual Kaware digelar sebagai bagian akhir dari perayaan pendirian rumah tinggal yang baru. Kepada laki-laki dewasa yang mendirikan rumah akan disuguhi tambelo sebagai tanda terima kasih. 


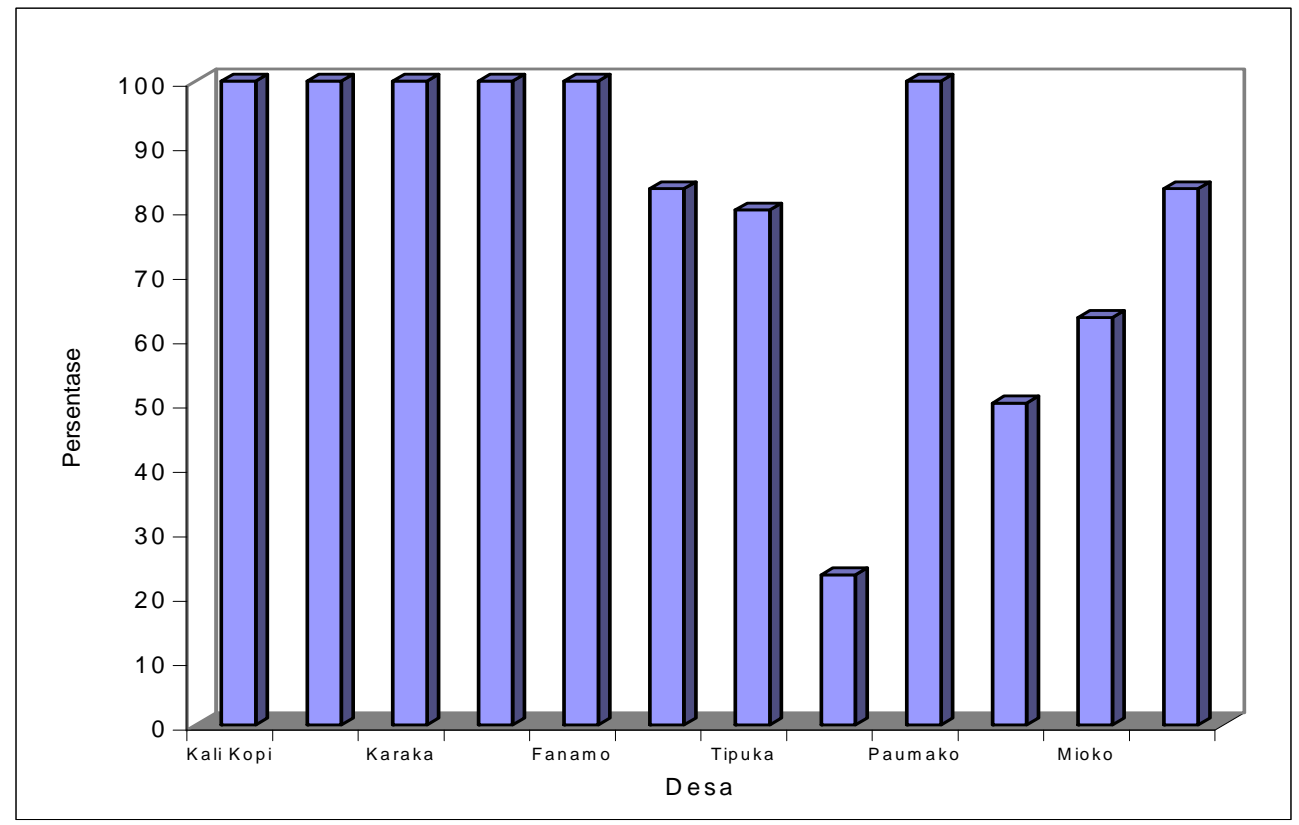

Gambar 1. Persentase Contoh yang Menyatakan TSK Harus Ada dalam Acara Adat

Hal yang sama dilakukan pula untuk acara ritual Ndoko, yaitu acara perintisan jalan-jalan setapak menuju daerah-daerah penangkapan atau dusun sagu baru, tambelo pada acara ini dimakan bersama oleh bapak, ibu dan anakanak.

Di Aikawapuka, TSK digunakan dalam acara ritual memperingati hari ke-3 meninggalnya warga desa. Meski jasad orang yang meninggal telah pergi tetapi kesan dan kenangan masih berada bersama masyarakat. Setiap ada warga desa yang meninggal, pada hari ketiganya dilakukan acara ritual adat memperingati berpulangnya warga. Pada acara ritual adat ini TSK disajikan bagi semua yang hadir dan dimakan bersama-sama dengan doa atau harapan agar semua keluarga dan warga yang ditinggalkan diberi kekuatan fisik dan kesehatan. Kesan-kesan baik dari warga yang meninggal diharapkan dapat menjadi inspirasi dan teladan bagi warga lainnya.

Pada Tabel 2 disajikan jenis-jenis moluska yang dipercaya penduduk bermanfaat dalam ritual adat setempat. Tambelo pilihan dimakan sebagai makanan pembuka (entri) dan siput dan kerang pilihan dimakan sebagai makanan utama. Budaya yang mengatur cara makan ini cukup rasional; karena tambelo enaknya dimakan segar sehingga sebaiknya memang segera dimakan atau dimakan lebih dulu sebelum makanan lainnya. Tambelo segar basah berair dimakan seperti menenggak mie panjang dimasukkan ke dalam mulut yang dapat menyegarkan kerongkongan dan menggu gah selera makan, sehingga memang selayak- nya tambelo menjadi entri atau makanan pembuka.

Tabel 2. J enis Tambelo, Siput dan Kerang serta Manfaat dalam Budaya Masyarakat

\begin{tabular}{|c|c|}
\hline Nama Latin (lokal) & $\begin{array}{c}\text { Manfaat atau Khasiat } \\
\text { Kesehatan }\end{array}$ \\
\hline \multicolumn{2}{|l|}{ A. Tambelo } \\
\hline $\begin{array}{l}\text { 1. Bactronophorus } \\
\text { thoracites }\end{array}$ & $\begin{array}{l}\text { Sebagai makanan pem- } \\
\text { buka pada saat acara adat } \\
\text { Karapao/ Arapao }\end{array}$ \\
\hline 2. Bankia orcutti & $\begin{array}{l}\text { Sebagai makanan pem- } \\
\text { buka pada saat acara adat } \\
\text { Karapao/ Arapao }\end{array}$ \\
\hline \multicolumn{2}{|l|}{ B. Siput } \\
\hline $\begin{array}{l}\text { 1. Telescopium } \\
\text { telescopium }\end{array}$ & $\begin{array}{l}\text { Sebagai makanan utama } \\
\text { pada saat acara adat } \\
\text { Karapao/ Arapao }\end{array}$ \\
\hline 2. Nerita balteata & $\begin{array}{l}\text { Sebagai makanan utama } \\
\text { pada saat acara adat } \\
\text { Karapao/ Arapao }\end{array}$ \\
\hline 3. Naquueita capulina & $\begin{array}{l}\text { Sebagai makanan utama } \\
\text { pada saat acara adat } \\
\text { Karapao/ Arapao }\end{array}$ \\
\hline \multicolumn{2}{|l|}{ C. Kerang } \\
\hline 1. Geloina sp & $\begin{array}{l}\text { Sebagai makanan utama } \\
\text { pada saat acara adat } \\
\text { Karapao/ Arapao }\end{array}$ \\
\hline 2. Geloina of Coaxan & $\begin{array}{l}\text { Sebagai makanan utama } \\
\text { pada saat acara adat } \\
\text { Karapao/ Arapao }\end{array}$ \\
\hline
\end{tabular}




\section{Manfaat bagi Kesehatan}

Pola mengonsumsi tambelo, siput dan kerang (TSK) telah umum pada masyarakat yang bermukim di kawasan muara Mimika, khususnya bagi Suku Kamoro dan Sempan. Dari 12 desa yang diteliti, responden dari 8 desa menyatakan bahwa tambelo mempunyai khasiat bagi kesehatan. Sisanya sebanyak 4 desa (Otakwa, Kaugapu, Aikawapuka dan Mioko) kurang dari $50 \%$ yang menyatakan bahwa tambelo berkhasiat untuk kesehatan bila dikonsumsi. (Tabel 3). Secara keseluruhan dari 12 desa yang diteliti, sebagian besar responden (70.7\% menyatakan bahwa tambelo bermanfaat untuk kesehatan. Tambelo yang enak dan sering dikonsumsi adalah Bactronophorus thoracites.

Tabel 3. Persentase Contoh yang Menyatakan Ada Manfaat Kesehatan Tambelo, Siput dan Kerang

\begin{tabular}{|l|r|r|r|}
\hline \multicolumn{1}{|c|}{ Desa } & Tambelo & Siput & Kerang \\
\hline 1. Kali Kopi & 83.3 & 56.7 & 70.0 \\
\hline 2. Pad XI & 90.0 & 53.3 & 66.7 \\
\hline 3. Karaka & 80.0 & 53.3 & 60.0 \\
\hline 4. Omawita & 100.0 & 10.3 & 10.3 \\
\hline 5. Fanamo & 93.3 & 16.7 & 13.3 \\
\hline 6. Otakwa & 46.7 & 0.0 & 6.7 \\
\hline 7. Tipuka & 76.7 & 43.3 & 10.0 \\
\hline 8. Kaugapu & 13.3 & 9.6 & 10.0 \\
\hline 9. Tipuka & 100.0 & 100.0 & 0.0 \\
\hline 10. Aikawapuka & 43.3 & 0.0 & 0.0 \\
\hline 11. Mioko & 46.7 & 0.0 & 0.0 \\
\hline 12. Atuka & 76.7 & 6.7 & 3.3 \\
\hline Total & 70.7 & 36.3 & 31.3 \\
\hline
\end{tabular}

Secara keseluruhan $36.3 \%$ responden menganggap siput memiliki khasiat untuk kesehatan bila sering dikonsumsi. Pada 4 desa (Kali Kopi, Pad XI, Karaka dan Paumako) lebih dari $50 \%$ responden menyatakan bahwa siput berkhasiat untuk kesehatan. Sementara di tiga desa (Otakwa, Aikawapuka, dan Mioko) tidak satupun responden menyatakan siput berkhasiat untuk kesehatan.

Untuk kerang, hanya 3 desa (KaliKopi, Pad XI dan Karaka) dari 12 desa yang lebih dari setengah $(60.0 \%-70.0 \%)$ respondennya menyatakan bahwa kerang berkhasiat untuk kesehatan. Bahkan ada 3 desa yang seluruh respondennya menganggap bahwa kerang sama sekali tidak berkhasiat untuk kesehatan yaitu Desa Tipuka/ Paumako, Aikawapuka dan Mioko. Secara keseluruhan dari 12 desa yang diteliti hanya $31.3 \%$ responden yang menganggap bahwa kerang berkhasiat untuk kesehatan.
Sekitar 96\% responden di Tipuka menganggap bahwa karaka/kepiting berkhasiat untuk kesehatan. Pada tiga desa (Otakwa, Aikawapuka dan Mioko) dari 12 desa yang diteliti seluruh respondennya menganggap bahwa karaka jika dikonsumsi tidak berkhasiat untuk kesehatan. Sekitar 26.0\% responden yang menganggap bahwa Karaka bila dikonsumsi akan bermanfaat untuk kesehatan.

Tidak semua jenis TSK dianggap memiliki khasiat untuk kesehatan. Khasiat tambelo jenis Bactronophorus thoracites menurut responden adalah untuk mencegah dan menyembuhkan sakit parah (serius) seperti sakit malaria, sakit pinggang/rematik dan batuk parah. Manfaat lain yang dirasakan oleh responden setelah mengonsumsi tambelo jenis ini adalah meningkatkan nafsu makan, kekuatan/stamina tubuh dan dapat meningkatkan produksi ASI ibu yang sedang menyusui. Tambelo jenis Bankia orcutti memiliki rasa pahit yang dianggap responden dapat menyembuhkan sakit batuk.

Dari berbagai jenis siput yang dikonsumsi penduduk lokal muara Mimika, siput jenis Telescopium telescopium, Nerita balteata dan Naquueita capulina dianggap oleh sebagian responden bermanfaat untuk kesehatan. Manfaat kesehatan mengonsumsi siput ini adalah dapat menambah tenaga, kekuatan atau memulihkan dan meningkatkan stamina tubuh bila dikonsumsi.

J enis kerang yang dianggap berkhasiat untuk kesehatan adalah Geloina sp, Geloina of Coaxan dan Archidae. Manfaat yang dirasakan setelah mengonsumsi ketiga jenis kerang tersebut adalah meningkatnya nafsu makan, mencegah malaria dan dapat meningkatkan stamina tubuh. Air rebusan Geloina sp bila disiramkan pada bagian yang luka dapat mempercepat proses penyembuhan luka. Selanjutnya ada satu jenis kerang yang mirip dengan Geloina sp ditemukan di Desa Aikawapuka yang dinamakan "Yaka" oleh penduduk setempat dan dianggap dapat menyembuhkan sakit lever bila dikonsumsi. Nama latin Yaka belum ditemukan dalam taksonomi moluska.

Meskipun dari segi zat-zat gizi yang dikandung tambelo, siput dan kerang dapat diperkirakan bahwa zat-zat gizi tersebut berperan dalam meningkatkan stamina, imunitas dan kesehatan tubuh, tetapi lebih baik lagi bila dibuktikan kebenaran persepsi masyarakat tersebut tentang berbagai khasiat kesehatan. Oleh karena itu perlu dilakukan penelitian lebih mendalam tentang kebenarannya, zat aktif gizi dan non-gizi yang bermanfaat dan bagaimana mekanisme kerjanya, khususnya 
untuk tambelo yang dianggap oleh masyakarat Kamoro sebagai "Pil Kamoro".

Tabel 4. J enis Tambelo, Siput dan Kerang serta Manfaat Kesehatannya yang Dipercaya Masyarakat

\begin{tabular}{|c|c|}
\hline Nama Latin (lokal) & $\begin{array}{c}\text { Manfaat atau Khasiat } \\
\text { Kesehatan }\end{array}$ \\
\hline \multicolumn{2}{|l|}{ A. Tambelo } \\
\hline $\begin{array}{l}\text { 1. Bactronophorus } \\
\text { thoracites }\end{array}$ & $\begin{array}{l}\text { Mencegah/menyembuhkan flu } \\
\text { dan malaria } \\
\text { Menyembuhkan sakit batuk } \\
\text { Menambah kekuatan/ stamina } \\
\text { Meningkatkan produksi ASI } \\
\text { Meningkatkan nafsu makan } \\
\text { Menyembuhkan sakit } \\
\text { pinggang dan rematik }\end{array}$ \\
\hline 2. Bankia orcutti & Menyembuhkan sakit batuk \\
\hline \multicolumn{2}{|l|}{ B. Siput } \\
\hline $\begin{array}{l}\text { 1. Telescopium } \\
\text { telescopium }\end{array}$ & Menambah kekuatan/ stamina \\
\hline 2. Nerita balteata & Menambah kekuatan/ stamina \\
\hline $\begin{array}{l}\text { 3. Naquueita } \\
\text { capulina }\end{array}$ & Menambah kekuatan/ stamina \\
\hline \multicolumn{2}{|l|}{ C. Kerang } \\
\hline 1. Geloina sp & $\begin{array}{l}\text { Menambah kekuatan/ stamina } \\
\text { Mempercepat penyembuhan } \\
\text { luka }\end{array}$ \\
\hline $\begin{array}{l}\text { 2. Geloina of } \\
\text { Coaxan }\end{array}$ & Menambah kekuatan/ stamina \\
\hline
\end{tabular}

\section{Cara Mengonsumsi}

Cara mengonsumsi tambelo, siput dan kerang oleh penduduk di wilayah ini sangat sederhana tanpa bumbu dan peralatan pengolahan, seperti dimakan segar, dibakar atau direbus. Pada Tabel 7 ditunjukkan bahwa sebagaian besar penduduk pada semua desa mengonsumsi tambelo dalam bentuk yang segar. Pada umumnya kebiasaan penduduk dalam mengonsumsi siput atau kerang lebih banyak diolah dengan membakar (27.4\%) daripada merebus $(9.2 \%)$.

Cara mengonsumsi tambelo adalah dengan membuang bagian kepalanya yang keras. Sebagian penduduk mengonsumsi seluruh bagian tambelo setelah dibuang bagian kepala (Gambar 3); dan sebagian lagi dengan cara mengonsumsi bagian tambelo setelah dibuang bagian kepala dan isi perut tambelo (Gambar 4). Penduduk yang mengonsumsi tambelo tanpa isi perutnya beranggapan bahwa mengkonsumsi tambelo dengan cara ini lebih berkhasiat dibanding mengonsumsi tambelo dengan isi perutnya. Selain itu mengonsumsi tambelo dengan cara ini lebih mudah ditelan karena ukuran tambelo jadi lebih kecil. Cara penduduk mengeluarkan isi perut tambelo adalah dengan cara mengurutnya dengan dua jari dari arah kepala ke ekor.

Tabel 5. Persentase Contoh menurut Cara Mengonsumsi

\begin{tabular}{|l|r|r|r|}
\hline \multicolumn{1}{|c|}{ Desa } & \multicolumn{1}{c|}{$\begin{array}{c}\text { Makan } \\
\text { Tambelo } \\
\text { Segar* }\end{array}$} & $\begin{array}{c}\text { Makan } \\
\text { Siput atau } \\
\text { Kerang } \\
\text { Dibakar* }\end{array}$ & $\begin{array}{c}\text { Makan } \\
\text { Siput } \\
\text { atau } \\
\text { Kerang } \\
\text { Direbus* }\end{array}$ \\
\hline 1. Kali Kopi & 20.0 & 30.0 & 6.7 \\
\hline 2. Pad XI & 66.7 & 63.3 & 0.0 \\
\hline 3. Karaka & 100.0 & 43.3 & 3.3 \\
\hline 4. Omawita & 0.0 & 3.4 & 0.0 \\
\hline 5. Fanamo & 33.3 & 13.3 & 10.0 \\
\hline 6. Otakwa & 76.7 & 13.3 & 23.3 \\
\hline 7. Tipuka & 90.0 & 20.0 & 23.3 \\
\hline 8. Kaugapu & 0.0 & 3.3 & 0.0 \\
\hline 9. Paumako & 96.6 & 13.8 & 20.7 \\
\hline 10. Aikawapuka & 40.0 & 43.3 & 6.7 \\
\hline 11. Mioko & 60.0 & 46.7 & 0.0 \\
\hline 12. Atuka & 86.7 & 33.3 & 16.7 \\
\hline Total & 54.2 & 27.4 & 9.2 \\
\hline
\end{tabular}

*Persentase terhadap yang makan

\section{Cara Memperoleh dan Lokasi Penangkapan}

Di kalangan Suku Kamoro memperoleh tambelo, siput dan kerang (TSK) dilakukan dengan cara mencari sendiri di daerah muara kawasan bakau di ulayat mereka. Di masa lalu, untuk mendapatkan TSK biasanya suatu keluarga pergi ke daerah muara dan mendirikan "kapiri kame" sebagai tempat tinggal sementara. Sebagian hasil tangkapan lansung dimakan, dan sebagian lagi dibawa pulang terutama siput dan kerang. Sekarang, kegiatan mencari TSK di kalangan suku Kamoro umumnya dilakukan oleh kaum wanita (ibu rumahtangga, remaja wanita), tidak lagi dilakukan dengan seluruh anggota keluarga. Ini juga salah satu faktor konsumsi TSK, terutama tambelo pada wanita lebih tinggi dibanding pada laki-laki.

Cukup banyak responden di lokasi penelitian yang memperoleh TSK dengan cara mencari sendiri (74.6 - 82.6\%). Hanya di Desa Omawita dan Kaugapu penduduk memperoleh TSK tidak dengan mencari sendiri (Tabel 6). Alasan responden di Kaugapu adalah karena jarak lokasi pemukiman dengan lokasi pencarian semakin jauh, dan sarana transportasi laut/ darat masih kurang, sedangkan di Omawita alasannya karena lingkungan yang berubah sehingga aroma TSK tidak seperti dulu lagi. 


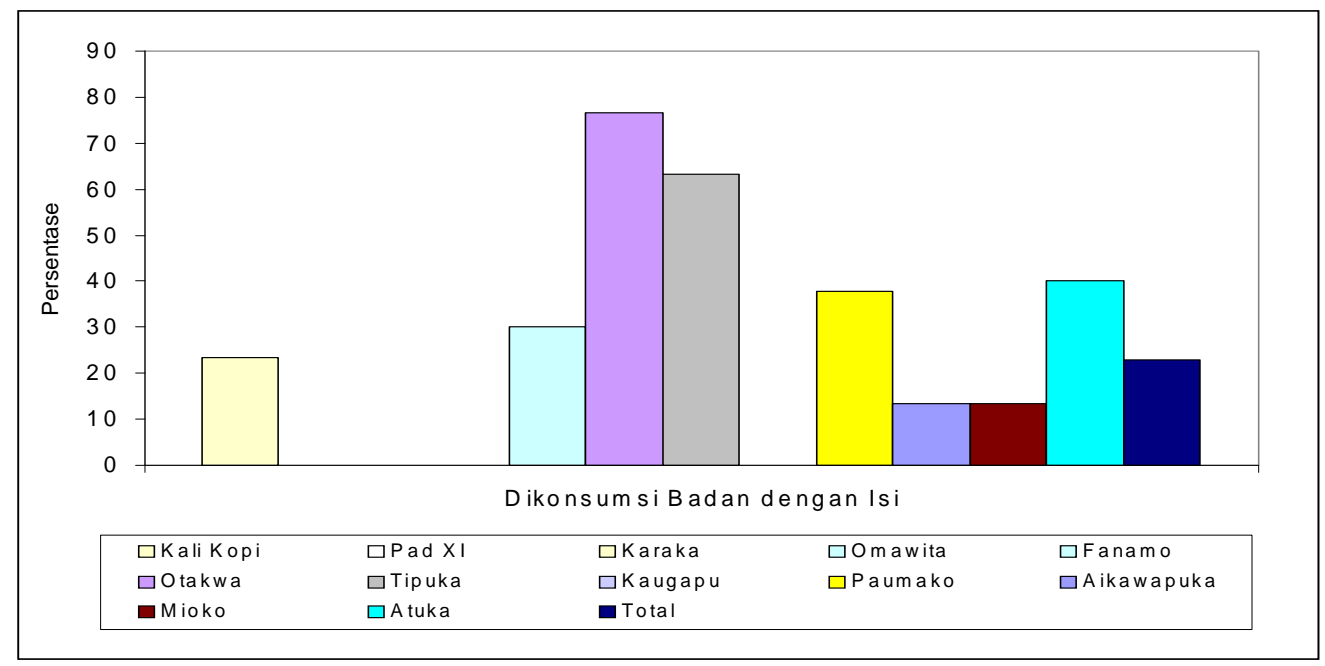

Gambar 3. Persentase Contoh yang Mengonsumsi Tambelo dengan Isi Perutnya

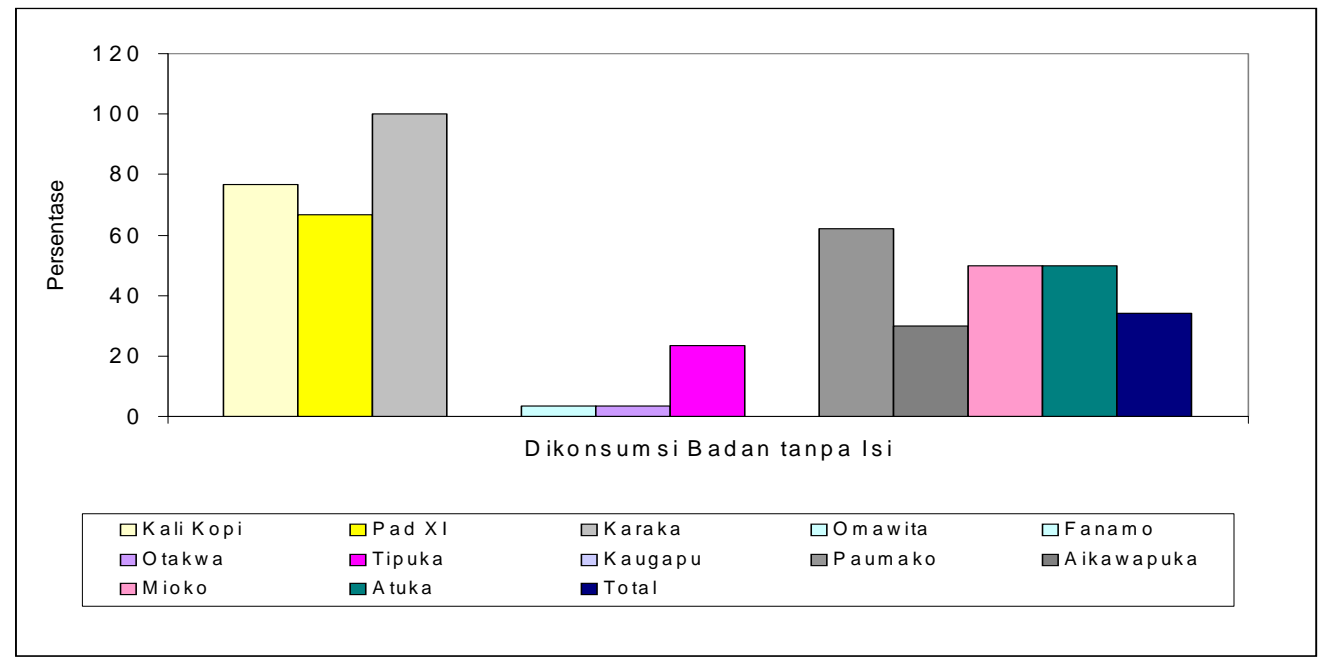

Gambar 4. Persentase Contoh yang Mengonsumsi Tambelo dengan Tanpa Isi Perut

Tabel 6. Persentase Contoh yang Mencari Tam belo, Siput dan Kerang dengan Cara Mencari Sendiri*

\begin{tabular}{|l|r|r|r|}
\hline \multicolumn{1}{|c|}{ Desa } & Tambelo & Siput & Kerang \\
\hline 1. Kali Kopi & 60.0 & 50.0 & 25.0 \\
\hline 2. Pad XI & 80.0 & 72.7 & 73.0 \\
\hline 3. Karaka & 96.6 & 95.0 & 97.3 \\
\hline 4. Omawita & 0.0 & 0.0 & 0.0 \\
\hline 5. Fanamo & 80.0 & 60.0 & 94.7 \\
\hline 6. Otakwa & 100.0 & 100.0 & 100.0 \\
\hline 7. Tipuka & 56.0 & 55.6 & 57.7 \\
\hline 8. Kaugapu & 0.0 & 0.0 & 0.0 \\
\hline 9. Paumako & 84.0 & 75.0 & 82.4 \\
\hline 10. Aikawapuka & 96.0 & 83.0 & 78.6 \\
\hline 11. Mioko & 76.5 & 66.7 & 56.3 \\
\hline 12. Atuka & 96.2 & 100.0 & 96.4 \\
\hline \multicolumn{1}{|c|}{ Total } & 82.6 & 74.6 & 80.3 \\
\hline
\end{tabular}

*) Persentase terhadap jumlah contoh yang makan
Daerah pencarian TSK yang digunakan penduduk terletak dalam ekosistem muara yang berbakau. Lokasi pencarian TSK ini membentang dari Barat (Atuka) sampai ke Timur (Otakwa). Penduduk umumnya memanfaatkan pinggiran sungai-sungai di muara sungai sebagai tempat untuk mencari TSK (Tabel 7).

Dari 12 desa yang disurvai, 6 desa menyatakan semakin sulit memperoleh TSK (Tabel 8). Desa-desa tersebut meliputi Kali Kopi, Omawita, Fanamo dan Kaugapu. Khusus Desa Kali Kopi, Omawita, dan Fanamo diakibatkan karena lingkungan perairan berubah sehingga citarasa TSK juga berubah. Hal ini menyebabkan penduduk harus pergi jauh (misal dari Omawita ke Inauga) mencari TSK dan karaka bila ingin mengonsumsinya. Dalam keadaan ini permasalahan hak ulayat menjadi kendala, bahkan sangat potensial menimbulkan konflik. 
Desa Kaugapu kesulitan memperoleh TSK disebabkan oleh jarak yang terlalu jauh antara lokasi pencarian TSK dan karaka dengan daerah pemukiman penduduk. Di samping itu, penduduk Desa Kaugapu telah beralih mata pencahariannya dari kegiatan ekstraktif ke kegiatan agraris dan sarana transportasi ke lokasi pencarian TSK tidak memadai.

Tabel 7. Lokasi Penangkapan Tambelo, Siput dan Kerang*)

\begin{tabular}{|c|c|c|}
\hline Penduduk Desa & Lokasi Mencari Tambelo & Lokasi Mencari Siput/Kerang \\
\hline 1. Kali Kopi & $\begin{array}{l}\text { Sungai Muamiua } \\
\text { Sungai Okoropa } \\
\text { Sungai Uturummapare } \\
\text { Sungai Yamaima }\end{array}$ & $\begin{array}{l}\text { Sungai Muamiua } \\
\text { Sungai Okoropa } \\
\text { Sungai Uturummapare } \\
\text { Sungai Yamaima }\end{array}$ \\
\hline 2. Pad XI & $\begin{array}{l}\text { Sungai Amakiri } \\
\text { Sungai Muamiua } \\
\text { Sungai Okoropa } \\
\text { Sungai Uturummapare } \\
\text { Sungai Yamaima } \\
\text { Sungai Yeremaya } \\
\text { Sungai Yamimapare } \\
\text { Sungai Wakonapoka }\end{array}$ & $\begin{array}{l}\text { Sungai Amakiri } \\
\text { Sungai Muamiua } \\
\text { Sungai Okoropa } \\
\text { Sungai Uturummapare } \\
\text { Sungai Yamaima } \\
\text { Sungai Yeremaya } \\
\text { Sungai Yamimapare } \\
\text { Sungai Wakonapoka }\end{array}$ \\
\hline 3. Karaka & $\begin{array}{l}\text { Sungai Muamiua } \\
\text { Sungai Okoropa } \\
\text { Sungai Yamaima }\end{array}$ & $\begin{array}{l}\text { Sungai Muamiua } \\
\text { Sungai Okoropa } \\
\text { Sungai Yamaima }\end{array}$ \\
\hline 4. Omawita**) & - & - \\
\hline 5. Fanamo & Sungai Inauga & Sungai Inauga \\
\hline 6. Otakwa & $\begin{array}{l}\text { Sungai Otakwa } \\
\text { Sungai Ohotya } \\
\text { Sungai Taraha } \\
\text { Sungai Wetakainipa }\end{array}$ & $\begin{array}{l}\text { Sungai Otakwa } \\
\text { Sungai Ohotya } \\
\text { Sungai Taraha } \\
\text { Sungai Wetakainipa }\end{array}$ \\
\hline 7. Tipuka & $\begin{array}{l}\text { Sungai Tipuka } \\
\text { Sungai Urumoparo } \\
\text { Sungai Yamakupu } \\
\text { Camp-1 } \\
\text { Portsite }\end{array}$ & $\begin{array}{l}\text { Sungai Tipuka } \\
\text { Sungai Urumoparo } \\
\text { Sungai Yamakupu } \\
\text { Camp-1 } \\
\text { Portsite }\end{array}$ \\
\hline 8. Kaugapu**) & - & - \\
\hline 9. Paumako & Sungai Paumako & Sungai Paumako \\
\hline 10. Aikawapuka & $\begin{array}{l}\text { Sungai Bupuku } \\
\text { Sungai Komako } \\
\text { Sungai Monta } \\
\text { Sungai Taraia }\end{array}$ & $\begin{array}{l}\text { Sungai Bupuku } \\
\text { Sungai Komako } \\
\text { Sungai Monta } \\
\text { Sungai Taraia }\end{array}$ \\
\hline 11. Mioko & $\begin{array}{l}\text { Sungai Aretaka } \\
\text { Sungai Komako } \\
\text { Sungai Yatire } \\
\text { Sungai Waikatiri } \\
\text { Sungai Waia } \\
\text { Kampus Biru }\end{array}$ & $\begin{array}{l}\text { Sungai Aretaka } \\
\text { Sungai Komako } \\
\text { Sungai Yatire } \\
\text { Sungai Waikatiri } \\
\text { Sungai Waia } \\
\text { Kampus Biru }\end{array}$ \\
\hline 12. Atuka & $\begin{array}{l}\text { Sungai Komako } \\
\text { Sungai Konokino } \\
\text { Sungai Wakatrimuka } \\
\text { Kampus Biru } \\
\text { Pamako }\end{array}$ & $\begin{array}{l}\text { Sungai Komako } \\
\text { Sungai Konokino } \\
\text { Sungai Wakatrimuka } \\
\text { Kampus Biru } \\
\text { Pamako }\end{array}$ \\
\hline
\end{tabular}

*) Habitat pencarian TSK sudah 'tercemar'

**) Aksesibilitas ke tempat pencarian TSK sulit 
Tabel 8. Persentase Contoh yang Menyatakan Semakin Sulit Memperoleh Tambelo, Siput dan Kerang*)

\begin{tabular}{|l|r|r|r|}
\hline \multicolumn{1}{|c|}{ Desa } & Tambelo & \multicolumn{1}{c|}{ Siput } & Kerang \\
\hline 1. Kali Kopi & 43.3 & 40.0 & 36.7 \\
\hline 2. Pad XI & 0.0 & 0.0 & 6.7 \\
\hline 3. Karaka & 0.0 & 0.0 & 0.0 \\
\hline 4. Omawita & 100.0 & 93.1 & 96.6 \\
\hline 5. Fanamo & 66.7 & 40.0 & 50.0 \\
\hline 6. Otakwa & 0.0 & 0.0 & 10.0 \\
\hline 7. Tipuka & 13.3 & 30.0 & 10.0 \\
\hline 8. Kaugapu & 100.0 & 100.0 & 96.7 \\
\hline 9. Paumako & 6.9 & 6.9 & 3.4 \\
\hline 10. Aikawapuka & 0.0 & 0.0 & 0.0 \\
\hline 11. Mioko & 0.0 & 0.0 & 0.0 \\
\hline 12. Atuka & 0.0 & 0.0 & 0.0 \\
\hline Total & 27.4 & 25.7 & 25.7 \\
\hline
\end{tabular}

*) Persentase terhadap jumlah contoh per desa

\section{KESIMPULAN DAN SARAN}

\section{Kesimpulan}

1. Konsumsi TSK mempunyai manfaat penting secara budaya dan kesehatan penduduk muara Mimika. Dari segi budaya TSK mempunyai manfaat intangible penting dalam berbagai acara adat. Tambelo (Bactronophorus thoracites dan Bankia orcutti) berperan sebagai makanan pembuka dalam berbagai acara adat; sementara siput (Telecopium telescopiu, Nerita balteata, dan Naqueita capicana) dan kerang (Geloina cf coaxan dan Geloina, sp) berperan sebagai makanan utama dalam berbagai acara adat.

2. Dari segi kesehatan, TSK dipercaya mempunyai aneka manfaat kesehatan. Secara umum TSK berkhasiat meningkatkan stamina. Khusus Geloina, sp juga berkhasiat untuk mempercepat penyembuhan luka. Tambelo Bactronophorus thoracites berkhasiat menyembuhkan sakit pinggang dan rematik, malaria, batuk dan flu; meningkatkan nafsu makan dan libido seksual (aprodisiak) dan meningkatkan produksi ASI bagi ibu menyusui sehingga dikenal dengan sebutan 'Pil Kamoro'.

3. Pada umumnya tambelo dikonsumsi dalam bentuk segar tanpa olahan. Sekitar seperlima (22.9\%) dari penduduk yang mengonsumsi tambelo selama seminggu yang lalu $(54.2 \%$ mengonsumsi tambelo segar dengan isi perutnya, yaitu di Desa Kalikopi, Fanamo, Otakwa, Tipuka, Paumako, Atuka, Aikawapuka dan Mioko. Siput dan kerang dikonsumsi setelah dibakar atau direbus.
4. Sebagian besar penduduk memperoleh TSK dengan cara mencari sendiri terutama oleh wanita (ibu dan remaja wanita). Pada umumnya tambelo, siput dan kerang dicari atau diramu di kawasan estuari Mimika di ekosistim mangrove. Penduduk di desa tertentu (Kalikopi, Omawita, Fanamo, Tipuka, Paumako dan Kagapu) beranggapan semakin sulit atau semakin jauh lokasi mencari tambelo.

\section{Saran}

1. Perlu kajian mendalam tentang komponenkomponen fungsional dalam TSK, terutama dalam tambelo yang disebut sebagai "Pil Kamoro" yang berkaitan dengan berbagai manfaat kesehatan yang dipercaya masyarakat $\mathrm{Mu}$ ara Mimika. Kajian ini mencakup identi- fikasi, isolasi, kompoisi, mekanisme dan uji klinik komponen yang dipercaya ber- manfaat tersebut.

2. Kawasan Barat (ke arah Atuka) dan Kawasan Timur (ke arah Otakwa) dari Muara Mimika, perlu dikembangkan menjadi lokasi konservasi dan pencarian TSK, agar sumber dan konsumsi lauk-pauk dan kudapan murah bagi penduduk lokal muara Mimika dapat berkelanjutan. Untuk ini perlu dilakukan kajian kebijakan dan program konservasi secara mendalam dan melibatkan pihak terkait.

3. Mempertimbangkan akan terjadi partumbuhan penduduk dan ekonomi yang pesat serta perubahan lingkungan perairan di kabupaten Mimika yang baru dimekarkan, dan memperhatikan kebiasaan penduduk mengonsumsi tambelo dalam bentuk segar dan dicelupkan ke air sebelum dimakan, diperlukan penyuluhan atau promosi cara sehat makan TSK bagi penduduk lokal secara berkesinambungan.

\section{UCAPAN TERMA KASIH}

Terima kasih penulis sampaikan kepada pimpinan PT Freeport Indonesia, khususnya kepada Dr. Wisnu Susetyo dan Dr. Dedi Mahdar, yang telah bekerjasama dan memberikan fasilitas penyelenggaraan penelitian ini.

\section{DAFTAR PUSTAKA}

Ends \& Gormukh. 2005. Basin Management Negotiated Approach. Cees Buys, Amsterdam. 
Gibney MJ, Vorster HH, \& Kok FJ. 2002. Introduction to Human Nutrition. Blackwell Science, Oxford.

Hardinsyah, Sumule A, \& Letsoin J. 2006. J enis dan jumlah konsumsi tambelo, siput dan kerang oleh penduduk di kawasan Muara Mimika, Papua. Jurnal Gizi dan Pangan, 1(1), 1-12.

Hardinsyah, Sumule A, Letsoin J , \& Barausau J . 2000. Laporan Survei Konsumsi Moluska di Muara dan Pantai Mimika. Institut Pertanian Bogor dan PT Freeport Indonesia, Bogor.

Hardinsyah, Khomsan A, Effendi YH, \& Saefudin A. 1998. Laporan Konsumsi Pangan Masyarakat Desa Sekitar PTFI. Institut Pertanian Bogor dan PT Freeport Indonesia, Bogor.

Effendi YH, Hardinsyah, \& Steve W. 1998. Aspek Kesehatan dan Gizi Masyarakat
Desa di Sekitar PTFI. Institut Pertanian Bogor dan PT Freeport Indonesia, Bogor.

http://id.wikipedia.org/ wiki/Kabupaten Mimi $\underline{\mathrm{ka}}$

Insel P, Turner RE, \& Ross D. 2002. Nutrition, 2002 Update. American Dietetics Association and Jones and Bartlett Publishers, Boston.

Markish SJ \& Camilleri C. 1996. Investigation of Metal Toxicity to Tropical Biota: Recommendations for Revision of Australian Water Quality Guidelines. A Report to Australian and New Zealand Environtment and Conservation Council Project.

Mitchell B, Setiawan B, \& Rahmi DH 2003. Pengelolaan Sumberdaya dan Lingkungan. Gajah Mada University Press, Yogyakarta. 